\title{
Cochrane
}

Library

Cochrane Database of Systematic Reviews

\section{Peribulbar versus retrobulbar anaesthesia for cataract surgery} (Review)

Alhassan MB, Kyari F, Ejere HOD

Alhassan MB, Kyari F, Ejere HOD.

Peribulbar versus retrobulbar anaesthesia for cataract surgery.

Cochrane Database of Systematic Reviews 2015, Issue 7. Art. No.: CD004083.

DOI: 10.1002/14651858.CD004083.pub3.

www.cochranelibrary.com

Peribulbar versus retrobulbar anaesthesia for cataract surgery (Review) 
TABLE OF CONTENTS

HEADER

ABSTRACT

PLAIN LANGUAGE SUMMARY

SUMMARY OF FINDINGS

BACKGROUND

OBJECTIVES

METHODS

Figure 1.

RESULTS

Figure 2.

Figure 3.

DISCUSSION

AUTHORS' CONCLUSIONS

ACKNOWLEDGEMENTS

REFERENCES

CHARACTERISTICS OF STUDIES

DATA AND ANALYSES

Analysis 1.1. Comparison 1 Peribulbar versus retrobulbar, Outcome 1 Pain score.

Analysis 1.2. Comparison 1 Peribulbar versus retrobulbar, Outcome 2 Globe akinesia.

Analysis 1.3. Comparison 1 Peribulbar versus retrobulbar, Outcome 3 Need for additional injection.

Analysis 1.4. Comparison 1 Peribulbar versus retrobulbar, Outcome 4 Local complications.

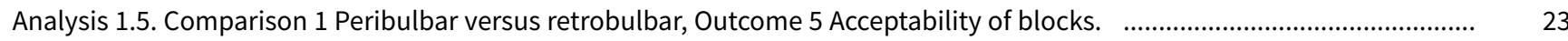

APPENDICES

WHAT'S NEW

HISTORY

CONTRIBUTIONS OF AUTHORS

DECLARATIONS OF INTEREST

SOURCES OF SUPPORT

INDEX TERMS 
[Intervention Review]

\section{Peribulbar versus retrobulbar anaesthesia for cataract surgery}

Mahmoud B Alhassan ${ }^{1}$, Fatima Kyari ${ }^{1}$, Henry OD Ejere ${ }^{2}$

${ }^{1}$ Clinical Ophthalmology, The National Eye Centre, Kaduna, Nigeria. ${ }^{2}$ Hode Internal Medicine, Texas, USA

Contact address: Mahmoud B Alhassan, Clinical Ophthalmology, The National Eye Centre, Western Bye Pass, Nnamdi Azikiwe Way, Kaduna, Kaduna State, PMP 2267, Nigeria.mbalhassan@yahoo.com.

Editorial group: Cochrane Anaesthesia Group.

Publication status and date: New search for studies and content updated (no change to conclusions), published in Issue 7, 2015.

Citation: Alhassan MB, Kyari F, Ejere HOD. Peribulbar versus retrobulbar anaesthesia for cataract surgery. Cochrane Database of Systematic Reviews 2015, Issue 7. Art. No.: CD004083. DOI: 10.1002/14651858.CD004083.pub3.

Copyright @ 2015 The Cochrane Collaboration. Published by John Wiley \& Sons, Ltd.

\section{A B S T R A C T}

\section{Background}

Cataract is a major cause of blindness worldwide. Unless medically contraindicated, cataract surgery is usually performed under local (regional) anaesthesia. Local anaesthesia involves the blockage of a nerve subserving a given part of the body. It involves infiltration of the area around the nerve with local anaesthetic. The two main approaches in the eye are retrobulbar and peribulbar. There is debate over whether the peribulbar approach provides more effective, safer anaesthesia for cataract surgery than retrobulbar block.

\section{Objectives}

The objective of this review was to assess the effects of peribulbar anaesthesia (PB) compared to retrobulbar anaesthesia (RB) on pain scores, ocular akinesia, patient acceptability and ocular and systemic complications.

\section{Search methods}

In the previous version of our review, we searched the databases until December 2007. In this updated version, we searched the Cochrane Central Register of Controlled Trials (CENTRAL) (March 2015); MEDLINE (1960 to March 2015); and EMBASE (1980 to March 2015$).$

\section{Selection criteria}

We included randomized controlled clinical trials comparing peribulbar anaesthesia and retrobulbar anaesthesia for cataract surgery.

\section{Data collection and analysis}

Two authors independently assessed trial quality and extracted data. We contacted trial authors for additional information, study methodology and missing data. We carried out a descriptive narrative of results as the included studies used varied methods for reporting the outcomes. We performed a subgroup analysis for globe akinesia.

\section{Main results}

We included six trials involving 1438 participants. Three of the six trials had adequate sequence generation while all the trials had unclear allocation concealment There was no evidence of any difference in pain perception during surgery with either retrobulbar or peribulbar anaesthesia. Both were largely effective. There was no evidence of any difference in complete akinesia or the need for further injections of local anaesthetic. Conjunctival chemosis was more common after peribulbar block (relative risk (RR) $2.11,95 \%$ confidence interval (CI) 1.46 to 3.05 ) and lid haematoma was more common after retrobulbar block (RR $0.36,95 \% \mathrm{Cl} 0.15$ to 0.88 ). Retrobulbar haemorrhage was uncommon and occurred only once, in a patient who had a retrobulbar block. 


\section{Authors' conclusions}

There is little to choose between peribulbar and retrobulbar block in terms of anaesthesia and akinesia during surgery measuring acceptability to patients, need for additional injections and development of severe complications. Severe local or systemic complications were rare for both types of block.

\section{PLAIN LANGUAGE SUMMARY}

\section{Comparison of two forms of local anaesthesia for cataract surgery}

Cataracts are the commonest cause of blindness, worldwide. A cataract is the clouding of the lens that causes loss of transparency of the eye. It is treated by removing the lens and replacing it with an artificial lens. Cataract surgery is usually performed under local anaesthetic, either peribulbar or retrobulbar anaesthesia. There is debate over whether the peribulbar approach provides more effective and safer anaesthesia for cataract surgery than retrobulbar block. Peribulbar anaesthesia is performed by injecting the anaesthetic drug in the orbit around the equator of the eye ball (globe). Retrobulbar anaesthesia is performed by injecting the anaesthetic drug in the orbit further back behind the eye ball, which is near the nerves that control eye movement and sensation.

We set out to compare the two forms of local anaesthesia for cataract surgery. Our review showed that pain control and paralysis of the eye muscles to paralyse movement of the eye ball (akinesia) and allow surgery are no different for the two types of anaesthesia. The need for additional injections of local anaesthetic was higher with peribulbar anaesthesia (four trials). Only one case of bleeding behind the eye occurred and this was with retrobulbar anaesthesia (in one trial). The acceptability of the two methods to patients were similar in the two studies that reported on this outcome. None of the trials reported any life-threatening complications. There was a moderate risk of bias in the included trials. 


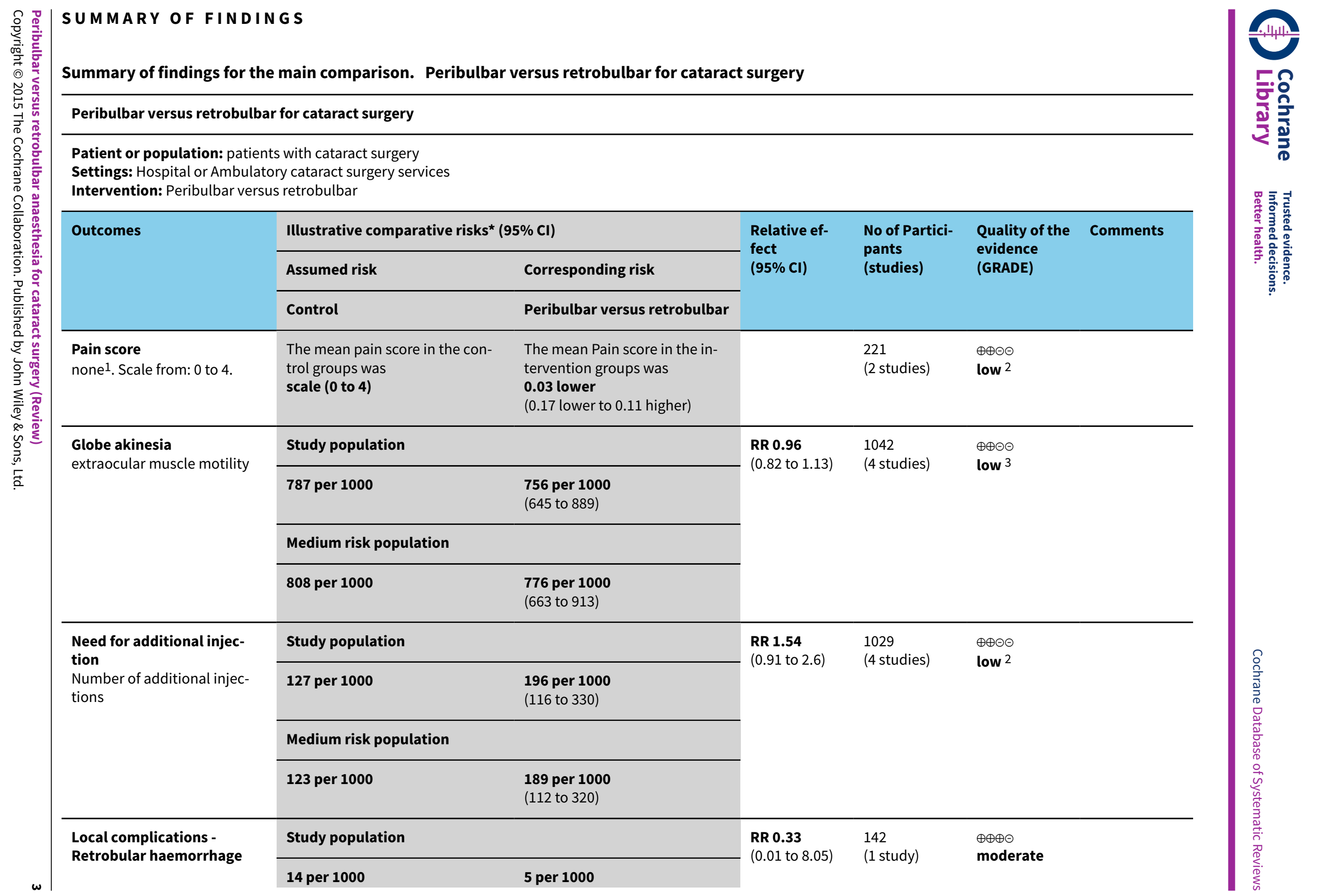




\begin{tabular}{|c|c|c|c|c|c|}
\hline 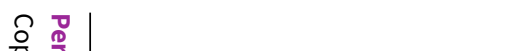 & & (0 to 113 ) & & & \\
\hline 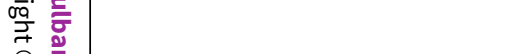 & Medium risk $\mathrm{p}$ & & & & \\
\hline 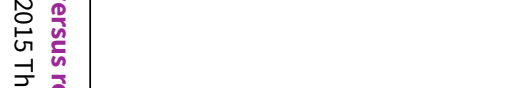 & 14 per 1000 & $\begin{array}{l}\mathbf{5} \text { per } \mathbf{1 0 0 0} \\
(0 \text { to } 113)\end{array}$ & & & \\
\hline Local complications - Con- & Study populat & & RR 2.11 & 1042 & $\oplus \oplus \oplus \ominus$ \\
\hline $\begin{array}{l}\text { presence of conjunctival } \\
\text { chemosis }\end{array}$ & 71 per 1000 & $\begin{array}{l}\mathbf{1 5 0} \text { per } \mathbf{1 0 0 0} \\
\text { (104 to } 217)\end{array}$ & & & \\
\hline 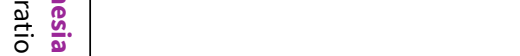 & Medium risk $\mathbf{p}$ & & & & \\
\hline 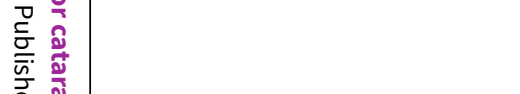 & 56 per 1000 & $\begin{array}{l}\mathbf{1 1 8} \text { per } 1000 \\
(82 \text { to } 171)\end{array}$ & & & \\
\hline Local complications - Ptosis & Study populat & & RR 1.06 & 317 & $\oplus \oplus \oplus \ominus$ \\
\hline 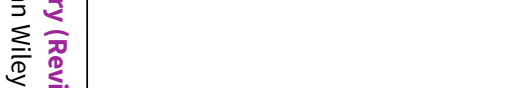 & 55 per 1000 & $\begin{array}{l}\mathbf{5 8} \text { per } \mathbf{1 0 0 0} \\
\text { (24 to } 143)\end{array}$ & & & \\
\hline & Medium risk $\mathbf{p}$ & & & & \\
\hline & 55 per 1000 & $\begin{array}{l}58 \text { per } 1000 \\
\text { (24 to } 143)\end{array}$ & & & \\
\hline Acceptability of blocks & Study populat & & RR 1.01 & 600 & $\oplus \oplus \oplus \ominus$ \\
\hline & 968 per 1000 & $\begin{array}{l}\mathbf{9 7 8} \text { per } \mathbf{1 0 0 0} \\
\text { (949 to } 997)\end{array}$ & & & \\
\hline & Medium risk $\mathbf{p}$ & & & & \\
\hline & 965 per 1000 & $\begin{array}{l}975 \text { per } 1000 \\
\text { (946 to } 994)\end{array}$ & & & \\
\hline
\end{tabular}

*The basis for the assumed risk (e.g. the median control group risk across studies) is provided in footnotes. The corresponding risk (and its $95 \%$ confidence interval) is based on the assumed risk in the comparison group and the relative effect of the intervention (and its $95 \% \mathrm{Cl}$ ). Cl: Confidence interval; RR: Risk ratio;

GRADE Working Group grades of evidence

High quality: Further research is very unlikely to change our confidence in the estimate of effect.

Moderate quality: Further research is likely to have an important impact on our confidence in the estimate of effect and may change the estimate.

Low quality: Further research is very likely to have an important impact on our confidence in the estimate of effect and is likely to change the estimate. 
Very low quality: We are very uncertain about the estimate.

1 on a scale of 0 to 4

2 Sequence generation and allocation concealment was inadequate

3 Allocation concealment and sequence generation not clear

4 Allocation concealment and masking was not adequate in 2 of the four trials

5 Sequence generation not clear 


\section{B A C K G R O U N D}

Cataract is the loss of transparency of the crystalline human lens. Cataracts are the major cause of blindness, worldwide, and approximately 20 million people were believed to be blind from cataract in 1999 (Foster 1999). The commonest type of cataract is age related. Other causes include trauma, intraocular inflammation and heredity. As there are no well-documented, effective ways of preventing age-related cataract, all efforts are toward providing surgery to those who need it. Cataract surgery involves removing the cataractous lens and thereby relieving visual impairment. The lens can be completely removed (intracapsular cataract extraction) or partially removed with the posterior capsule of the lens remaining (extracapsular cataract extraction). The extracapsular technique permits insertion of an artificial intraocular lens.

Unless medically contraindicated, cataract surgery is usually performed under local (regional) anaesthesia. Local anaesthesia is the blockage of a nerve subserving a given part of the body by infiltrating the area around the nerve with local anaesthetic. In the eye, the periocular area is infiltrated to block all the nerves around the globe. The goal is safe, painless, efficient and effective local anaesthesia (Hamilton 1988). There are different approaches to the delivery of local injections to produce anaesthesia for cataract surgery. The two main approaches are retrobulbar and peribulbar. The retrobulbar approach appears to be more commonly practiced but there is an increasing tendency to use peribulbar anaesthesia, which is claimed to provide the same degree of akinesia and anaesthesia as retrobulbar injection (Hessemer 1994). Although newer techniques of administering local anaesthesia for cataract surgery, such as sub-tenons and topical or intracameral application, are gaining popularity, peribulbar or retrobulbar anaesthesia is still the technique of choice in several parts of the world (Hansen 1998; Leaming 1999).

\section{Techniques}

\section{Retrobulbar anaesthesia}

Retrobulbar anaesthesia (RB) is produced by delivering the local anaesthetic agent into the space behind the eye. This space is enclosed by the muscles that move the eye. It also contains the optic nerve, the nerves that control eye muscle contraction and the sensory nerves that supply sensation to the globe and its surrounding structures (Springs 2001).

\section{Peribulbar anaesthesia}

Peribulbar anaesthesia (PB) is given by delivering the local anaesthetic agent outside the muscle cone (Davis 1986; Fry 1990).

There is debate over whether the peribulbar approach provides more effective, safer anaesthesia for cataract surgery than does retrobulbar block. It is recognized that use of the retrobulbar approach may be associated with potentially serious ocular damage due to the blind insertion of a needle into the intraconal space. This is the space behind the eye, formed by the extraocular muscles, that contains the major nerves of the eye and its adnexa. The risks include scleral perforation, stimulation of the oculocardiac reflex and injection of anaesthetic agent into the perioptic meningeal space. However, this route may have the advantage of rapid onset of analgesia and akinesia with the use of relatively smaller volumes of anaesthetic agent (Ali-Melkkila
1992). Like the retrobulbar approach, peribulbar anaesthesia aims to ensure ocular akinesia (eye stability) and anaesthesia during surgery; it is considered by some to be safer than retrobulbar anaesthesia (Davis 1989; Murdoch 1990; Whitsett 1990). Peribulbar block is thought to be associated with fewer incidences of serious complications but may have a slower onset of anaesthesia and require larger volumes of anaesthetic agent. Both approaches, however, may have potentially sight and lifethreatening complications (Davis 1994). This systematic review set out to summarize the best available evidence for the effects of peribulbar anaesthesia and retrobulbar anaesthesia for cataract surgery. Previous reviews were deficient in accounting for biases which may have been present in the clinical trials, thus making their findings unreliable. Friedman et al did an extensive review of the literature to assess the effectiveness of regional anaesthesia for cataract surgery but the review searched for trials only up to 1999 and did not assess the need for additional injections (Friedman 2001a; Friedman 2001b).

\section{O B JECTIVES}

The objective of this review was to assess the effects of peribulbar anaesthesia compared to retrobulbar anaesthesia on pain scores, ocular akinesia, patient acceptability and ocular and systemic complications.

\section{METHODS}

\section{Criteria for considering studies for this review Types of studies}

We included randomized controlled clinical trials (RCTs) comparing retrobulbar block to peribulbar block for cataract surgery.

\section{Types of participants}

We included patients undergoing cataract surgery.

\section{Types of interventions}

We included trials comparing peribulbar block to retrobulbar block for cataract surgery. Peribulbar block included all its various modifications, as described by Ali-Melkkila 1993 and Davis 1989.

\section{Types of outcome measures}

\section{Primary outcomes}

1. Pain: experienced during surgery and measured using a visual analogue scale (VAS) (1 to 10) or any other method as described in the primary report.

2. Ocular akinesia: the degree to which the ocular muscles were paralysed and the eye immobilized, i.e. complete akinesia.

3. Acceptability of block to patients: the number of participants who reported that the blocks were acceptable to them.

\section{Secondary outcomes}

1. Need for supplemental injection (of local anaesthetic): the number of additional injections given in order to achieve good akinesia.

2. Complications of the procedure as reported by the primary investigators and classified into:

a. local complications measured as the number of participants in whom local complications were observed during or after 
administration of a local anaesthetic (examples include retrobulbar haemorrhage, globe perforation, optic nerve damage, raised orbital pressure);

b. systemic complications measured as the number of participants in whom systemic complications arose during or after administration of a local anaesthetic (examples include respiratory depression, cardiopulmonary arrest).

\section{Search methods for identification of studies}

In the previous version of our review, we searched all the databases until December 2007.

In this updated version we searched the Cochrane Central Register of Controlled Trials (CENTRAL) (March 2015); MEDLINE (1960 to March 2015); and EMBASE (1980 to March 2015). Our search strategies are listed in Appendix 1; Appendix 2; and Appendix 3.

We searched the Cochrane Anaesthesia Review Group Specialized Register using the terms: anaesthesia with local or regional or retrobulbar or intraconal or peribulbar or periocular. We then combined these terms with: cataract or intraocular lens or halogenous.

We searched both CENTRAL and MEDLINE using the MeSH terms: anaesthesia, local; and the text terms: retrobulbar anaesthesia or block, peribulbar anaesthesia or block, intraconal or periocular. We then combined these terms with the following MeSH terms: cataract extraction or lens implantation, intraocular; and the text terms: cataract surgery, cataract extraction, senile cataract or agerelated cataract or halogenous.
We searched EMBASE using the MeSH terms: regional anaesthesia (exploded, which includes the term retrobulbar anaesthesia), topical anaesthesia (exploded), peribulbar anaesthesia; and the text terms: retrobulbar anaesthesia or block, peribulbar anaesthesia or block, intraconal or periocular. These terms were then combined with the following MeSH terms: cataract extraction (exploded), senile cataract, lens implant; and the text terms: cataract surgery, cataract extraction, senile cataract or age-related cataract or halogenous.

We searched the reference lists of identified trials to find additional trials. We used the Science Citation Index to find studies that cited the identified trials. We contacted the primary investigators of identified trials for information on additional trials.

We did not apply any language restriction.

\section{Data collection and analysis}

\section{Selection of trials}

Two authors (MA and FK) independently screened the titles and abstracts identified from the searches. We resolved differences by consulting with the third author (HE).

We obtained full copies of potentially relevant trials. We assessed the full copies according to the 'Criteria for considering studies for this review'. We then assessed trials meeting these criteria for methodological quality. We resolved differences by consulting with the third author (HE).Figure 1 
Figure 1. Study flow diagram.

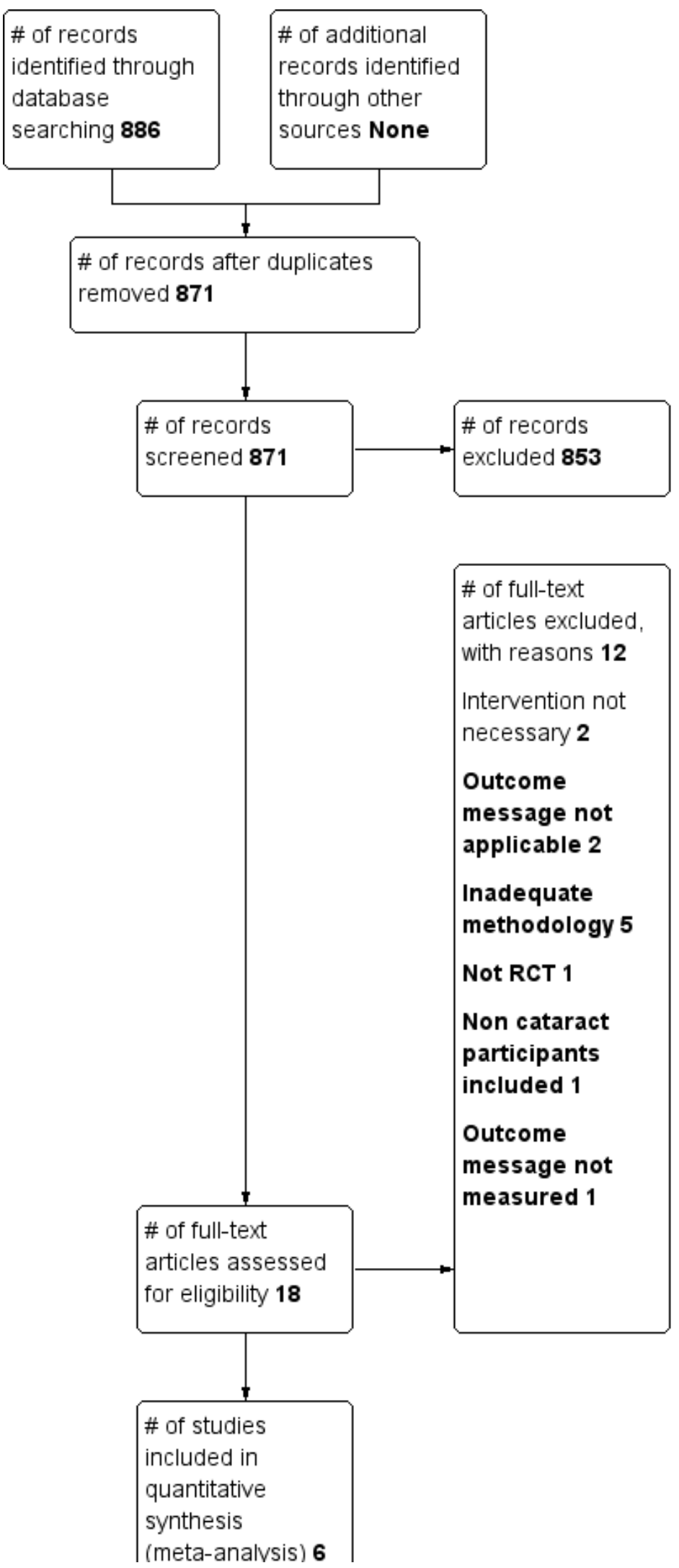


Figure 1. (Continued)

\section{synthesis \\ (meta-analysis) 6}

\section{Assessment of methodological quality}

In our previous version we graded trial quality as: A - low risk of bias; B - moderate risk of bias; C - high risk of bias.

In this updated version of the review we assessed the quality of included RCTs following the Cochrane approach. We used the methods detailed in Chapter Eight of the Cochrane Handbook for Systematic Reviews of Interventions (Higgins 2009). We considered the following variables: allocation concealment; masking of participants and primary investigators (eye surgeons); completeness of follow up; and masking of outcome assessment. Masking is accomplished by ensuring that only the anaesthetist or ophthalmologist (who does not determine eligibility and is not responsible for outcome assessment) provides the block according to a randomly generated schedule.

We assessed trial quality as: 'yes' indicating that the study met that quality parameter, 'no' it did not, or 'unclear' indicating that there was insufficient evidence to make a judgement either way. We contacted investigators for variables graded as unclear. Two authors (MA and FK) assessed trial quality independently; a third author (HE) helped to resolve any disagreements.

\section{Data collection}

Two authors (MA and FK) independently extracted data into a form developed specifically for the review. We resolved discrepancies by discussion. We extracted data, as far as possible, on the basis of an intention-to-treat analysis. We contacted primary investigators for missing data. Two authors (MA and FK) independently entered all data into Review Manager (RevMan 5.0). We resolved disagreements by discussion that reached a consensus.

\section{Data synthesis}

\section{Summary statistics}

We calculated mean difference (MD) for continuous variables and relative risk (RR) for dichotomous variables.

\section{Heterogeneity}

We assessed heterogeneity using the $1^{2}$ statistic. We defined significant heterogeneity as an $\mathrm{I}^{2}$ statistic greater than $50 \%, \mathrm{P}$ value of less than 0.1 . We calculated a pooled summary estimate using a fixed-effect model where there was no significant heterogeneity. Where there was significant heterogeneity, and depending on the number of trials included, we used a random-effects model.

\section{Sensitivity analysis}

We planned to perform a sensitivity analysis by including and excluding trials without concealment of allocation. If there were enough trials, we had planned to assess the effects of sedation, age, number of injection sites, and volume of anaesthetic agent used on the outcome measures.

A narrative summary of trial results was presented when the variables were reported in a diverse way or if only one trial reported a variable.

\section{Inclusion and exclusion criteria}

We included and excluded studies according to the criteria for considering studies for this review and the methodological quality assessment of the trials, that is: allocation concealment; masking of participants and investigators; completeness of follow up; and masking of outcome assessment.

1. We included only RCTs.

2. We excluded trials comparing peribulbar or retrobulbar anaesthesia with any others forms of anaesthesia for cataract surgery.

3. We included trials with unclear allocation concealment if the other methodological qualities were adequate.

4. We excluded trials in which cataract surgery was combined with any other ocular surgery.

\section{RES U L T S}

\section{Description of studies}

We identified a total of 871 citations from the database searches, manual searches and citation review (Figure 2). After screening the citations by title and then abstract, we obtained full paper copies for 22 study reports that were potentially eligible for inclusion in the review. Of these, 12 were excluded for the reasons described in the table 'Characteristics of excluded studies'. We did not identify any ongoing study. Four trials are awaiting assessment because we have not yet obtained full papers (see 'Characteristics of studies awaiting classification'). Six studies met our inclusion criteria. The six studies enrolled 1438 patients. For full details of the six included studies see the table 'Characteristics of included studies'. All the trials had unclear allocation concealment while three trials had adequate sequence generation. The studies fell broadly into two groups: studies with adequate allocation of concealment (three trials); and those with unclear allocation concealment (three trials). 
Figure 2. Risk of bias graph: review authors' judgements about each risk of bias item presented as percentages across all included studies.

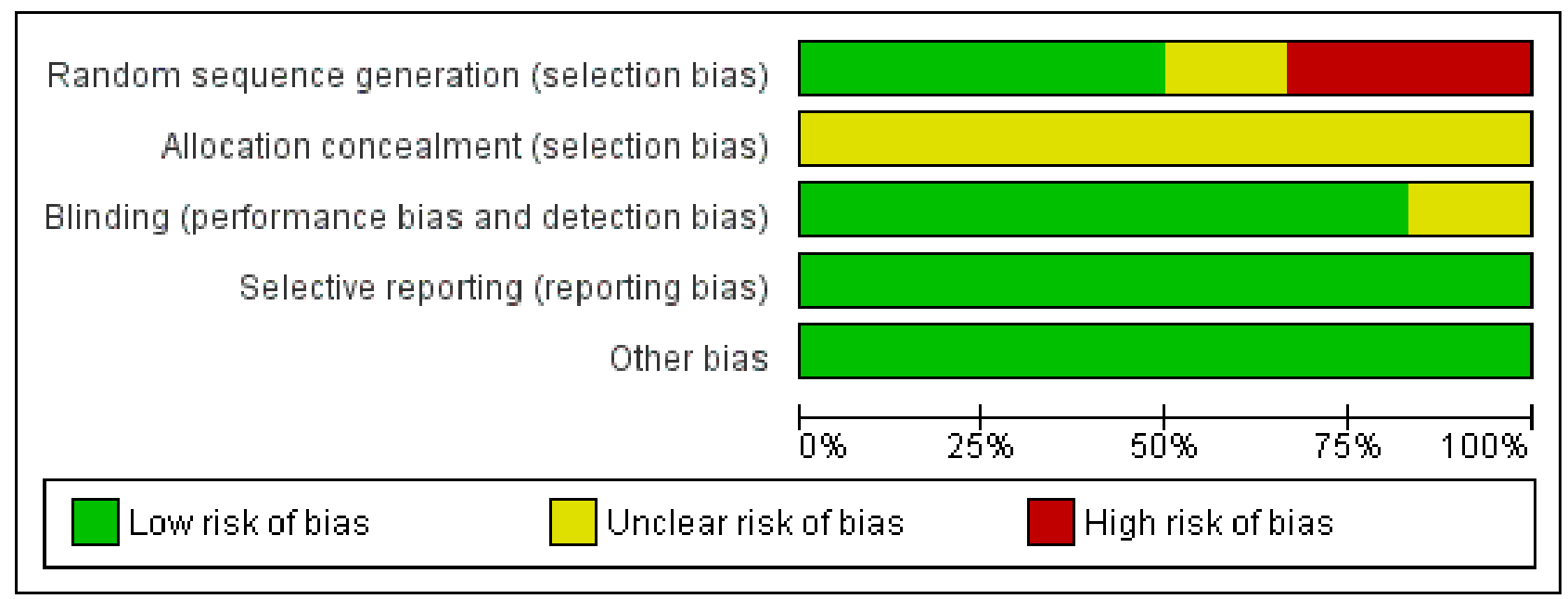

\section{Interventions}

All the studies were hospital based. One study used lidocaine alone as anaesthetic agent while the others used a combination of lidocaine and either bupivacaine or mepivacaine and bupivacaine (see 'Characteristics of included studies'). Sedation was given before injection of the local anaesthetic in two trials (Ali-Melkkila 1992; Weiss 1989).

\section{Outcome measures}

The pain score was assessed in three trials (Athanikar 1991; Weiss 1989; Wong 1993). This pain score assesses the level of pain as reported by the participant during cataract surgery. Athanikar 1991 graded globe anaesthesia on a scale of 0 to +++, where 0 was inadequate anaesthesia for continuing with surgery; + was not ideal but adequate to continue; ++ was not ideal but more than adequate to continue; and +++ was total anaesthesia. Weiss 1989 rated globe anaesthesia on a four-point scale, where 4 meant total anaesthesia; 3 meant more than adequate but not quite total; 2 meant not ideal but just adequate to proceed; and 1 meant inadequate to proceed. Wong 1993 graded globe anaesthesia as: optimal; not optimal but able to proceed; and not optimal and unable to proceed.
Globe akinesia was assessed in five trials (Ali-Melkkila 1992; AliMelkkila 1993; Athanikar 1991; Weiss 1989; Wong 1993). Grade 'A' block was defined as a total block with no movement of the eye ball; grade ' $B$ ' block was defined as movement of the eye ball that was not severe enough to prevent the surgery; grade ' $C$ ' block was defined as movement of the eye ball with a need for additional injections. Counts for Grade 'A' block (complete akinesia) were used for summary statistics for globe akinesia. This is because RevMan 5.0 does not support ordinal variables.

Need for supplemental injection was assessed in four trials (AliMelkkila 1992; Ali-Melkkila 1993; Weiss 1989; Wong 1993).

Complications resulting from the two anaesthetic interventions were reported in all the studies except Weiss 1989.

Patient acceptability of the two interventions was reported in the Ali-Melkkila 1992 and Wong 1993 trials. Ali-Melkkila 1992 assessed a patient's acceptability by asking whether the participant preferred general anaesthesia to local anaesthesia; while Wong 1993 asked whether the participant would have the same block again.

\section{Risk of bias in included studies}

(see 'Characteristics of included studies'; Figure 2; Figure 3). 
Figure 3. Risk of bias summary: review authors' judgements about each risk of bias item for each included study.

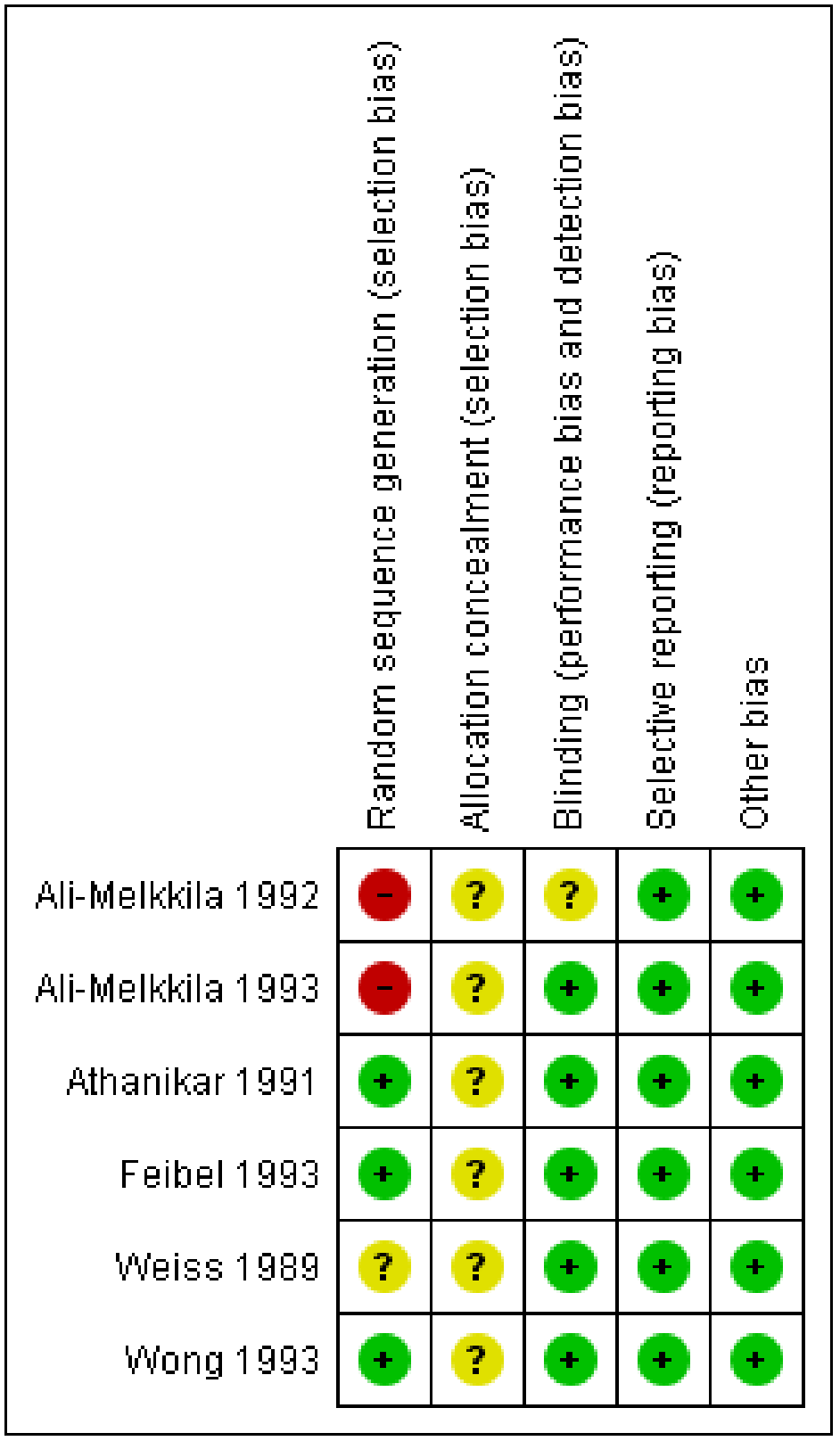

Ali-Melkkila 1992 randomized 300 patients to receive either periocular or retrobulbar anaesthesia. The concealment of allocation was not clear in the report. However, masking of participants and primary investigators, completeness of follow up and masking of outcome assessment were adequate.

Ali-Melkkila 1993 randomized 450 patients to receive either periocular or retrobulbar anaesthesia. The concealment of allocation was unclear in the report. The periocular group was further divided into two groups (P1 and P2). The masking of participants and primary investigators and masking of outcome assessment were adequate.

Athanikar 1991 randomized 142 patients to receive either one-point low volume peribulbar anaesthesia or retrobulbar anaesthesia using a randomization chart. Separate individuals carried out the administration and the assessment. The masking of outcome assessment was adequate.

Feibel 1993 randomized 317 patients to receive either peribulbar or retrobulbar anaesthesia by the use of a coin toss. The masking of participants and primary investigators and masking of outcome assessment were adequate. The completeness of follow up was adequate.

Weiss 1989 randomized 79 patients to receive either peribulbar or retrobulbar anaesthesia. The method of allocation was unclear. Masking of participants and primary investigators, completeness of follow up and masking of outcome assessment were adequate.

Wong 1993 randomized 150 patients to receive either retrobulbar, peribulbar or modified retrobulbar anaesthesia. The allocation concealment was adequate. Masking of participants and primary 
investigators and masking of outcome assessment were adequate. The modified RB consisted of a single needle insertion superomedially through the upper lid at a point midway between the medial canthus and the supraorbital notch and the needle then advanced slowly in the sagittal plane to a depth of 32 to $33 \mathrm{~mm}$.

\section{Effects of interventions}

See: Summary of findings for the main comparison Peribulbar versus retrobulbar for cataract surgery

A total of 1438 participants were included in the review. There was significant heterogeneity in the grading system used for outcome measures amongst the included trials. Data were pooled where the grading system was similar. The third author was contacted three times to resolve disagreements on whether to include or exclude a trial. We contacted five authors for further information. There was no response from three whilst the letters were returned from two addresses stating 'No longer at this address' (see Summary of findings table 1).

\section{Pain score}

(see Analysis 1.1)

Pain control during surgery (globe anaesthesia) was no different between retrobulbar anaesthesia and peribulbar anaesthesia.

Two trials involving 221 participants reported on pain scores (Athanikar 1991; Weiss 1989) (see Analysis 1.1). The pooled summary effect was a weighted mean difference (WMD) of - 0.03 $(95 \% \mathrm{Cl}-0.17$ to 0.11$)$. There was no significant heterogeneity $\left(\mathrm{Chi}^{2}=\right.$ $0.63, \mathrm{P}=0.43)$. In Wong 1993 the rates of optimal anaesthesia were: RB 93/100 (0.93) and PB 49/50 (0.98).

\section{Globe akinesia}

(see Analysis 1.2)

There was no difference in the rate of complete akinesia with the two types of anaesthesia. Five trials reported akinesia as an outcome measure. One trial (Weiss 1989) assessed akinesia as a mean score and the mean scores were: peribulbar anaesthesia 2.96 (standard deviation (SD)1.4); retrobulbar anaesthesia 3.76 (SD $0.43)$. In this trial RB gave better akinesia than PB. Four trials (Athanikar 1991; Ali-Melkkila 1992; Ali-Melkkila 1993; Wong 1993) involving a total of 1042 participants were analysed for presence of complete akinesia. Athanikar 1991 was not included in the pooled summary effect because all the participants had complete akinesia for the two interventions. The pooled summary effect for grade ' $A$ ' blocks was RR $0.96(95 \% \mathrm{Cl} 0.82$ to 1.13$)$ using a random-effects model. The test for heterogeneity was significant $\left(P=0.01,1^{2}=\right.$ $77.9 \%)$. The overall effect was not significant $(P=0.62)$. A sensitivity analysis was not done because of the small number of included trials.

\section{Need for supplemental injection}

(see Analysis 1.3)

Four trials ( Ali-Melkkila 1992; Ali-Melkkila 1993; Weiss 1989; Wong 1993) reported supplemental blocks amongst a total of 1029 participants. The direction of effect favoured peribulbar anaesthesia in Wong 1993 whilst it favoured retrobulbar anaesthesia in the other three trials. The pooled summary statistic was RR 1.54 (96\% Cl 0.91 to 2.60) using a random-effects model. There was significant heterogeneity $\left(\mathrm{Chi}^{2}=7.94, \mathrm{P}=0.05, \mathrm{1}^{2}=\right.$ $62.2 \%)$. The summary RR was not significant $(P=0.11)$ (see Analysis 1.3).

\section{Complications}

(see Analysis 1.4)

\section{Local}

Retrobulbar haemorrhage was reported in $1 / 71(0.3 \%)$ participants in the retrobulbar group, in one trial (Athanikar 1991). There was no report of retrobulbar haemorrhage in the peribulbar group.

Conjunctival chemosis was documented in four trials (Athanikar 1991; Ali-Melkkila 1992; Ali-Melkkila 1993; Wong 1993). The risk for conjunctival chemosis was $17.4 \%(98 / 563)$ in the PBs and $7.1 \%$ (34/479) in the RBs. The mean volume of anaesthetic solution used for the blocks was $8.3 \mathrm{ml}$ and $4.7 \mathrm{ml}$, respectively. The RR (fixedeffect model) was 2.11 ( $95 \% \mathrm{Cl} 1.46$ to $3.05 ; \mathrm{P}<0.00001)$. There was no significant heterogeneity $(12=31.9 \%)$ (see Analysis 1.4$)$. The risk for conjunctival chemosis was more with PB than RB. This may be due to more anterior delivery of anaesthetic agent in the orbit and the generally larger volume of anaesthetic injected.

One trial (Ali-Melkkila 1993) reported lid haematoma as a local complication. The risk for lid haematoma was $2.7 \%(8 / 300)$ in the PBs and $7.3 \%(11 / 150)$ in the RBs. The rate was much higher in RB than PB ( $P=0.03)$ (see Analysis 1.4).

Persistent ptosis (measured as the amount of decrease in the lid fissure drop at 90 days after surgery, where it was equal to or greater than $2 \mathrm{~mm}$ ) occurred in nine (1.1\%) of the participants in the peribulbar group and nine (1.3\%) participants in the retrobulbar group. There was no difference in the risk of having ptosis (RR $1.06,95 \% \mathrm{Cl} 0.43$ to $2.60 ; \mathrm{P}=0.9$ ). Only one study reported on this outcome (Feibel 1993).

\section{Systemic}

No major systemic complications were reported in any of the trials.

\section{Effect of sedation}

Pain control and globe akinesia were no different between the participants that received sedation and those that did not. In Ali-Melkkila 1992 each patient received alfentanil 15 minutes before anaesthesia whilst in Weiss 19890.5 to $1 \mathrm{mg}$ of intravenous idazolam was administered before anaesthesia.

\section{Acceptability of block}

(see Analysis 1.5)

There was no difference in the number of participants who reported the block to be acceptable between the two anaesthetic techniques (see Analysis 1.5). Ali-Melkkila 1992 and Wong 1993 reported acceptability of the block for the two interventions. In the peribulbar group $98.5 \%$ (345/350) accepted the block whilst in the retrobulbar group $96.8 \%(242 / 250)$ accepted the block. The RR (fixed-effect model) was 1.01 ( $95 \% \mathrm{Cl} 0.98$ to 1.03$)$. The test for heterogeneity showed no significant heterogeneity $\left(\mathrm{Chi}^{2}=1.55, \mathrm{P}=\right.$ $0.21,12=35.3 \%)$. 


\section{DISCUSSION}

Historically, retrobulbar anaesthesia has been associated with good anaesthesia and eye ball paralysis but severe local and systemic complications. This led to the development of peribulbar anaesthesia and modified techniques that were thought to be equally effective in producing both akinesia and anaesthesia with less severe globe or life-threatening complications. The objective of this review was to provide evidence for this assertion. Earlier non-systematic reviews have not provided convincing evidence on the relative efficacy of retrobulbar and peribulbar anaesthesia for cataract surgery (Friedman 2001a). Friedman 2001b assessed study quality and eligibility for inclusion but three studies with high risk of bias were included in their review (Murdoch 1990; Saunders 1993; Whitsett 1990).

In the present review, we did not find any difference in pain control (globe anaesthesia) between PB and RB (WMD - 0.03, 95\% Cl - 0.17 to 0.11 ). For globe akinesia grade 'A' block, that is a total block with no movement of the eye ball, the rates were similar with the two techniques (RR $1.04,95 \% \mathrm{Cl} 0.89$ to 1.22 ); see Summary of findings for the main comparison. This is similar to the findings in the Friedman review where they found that there was no difference in rate of complete akinesia or the ability of $\mathrm{PB}$ and RB to provide pain control during cataract surgery (Friedman 2001a).

In the present review planned preanaesthesia sedation did not affect the pain score or akinesia; in the two trials in which it was used. The need for additional injection was higher with PB than for RB (RR 1.54, 95\% Cl 0.91 to 2.60). This trend was consistent in three of the included trials. This difference was not, however statistically significant (see Summary of findings table 1). Friedman 2001a did not report on this outcome in their review. Evidence could not be provided for retrobulbar haemorrhage because it was reported in only one patient, in the Athanikar 1991 trial. Persistent ptosis rate was similar between techniques in Feibel 1993. There is some evidence that conjunctival chemosis occurs more often after PB than RB; this was statistically significant $(P<0.00001)$. No major systemic complication were reported in the included trials (see Summary of findings for the main comparison).

The strength of the evidence in this review is low for pain score, akinesia and need for additional injection. This is due to the poor methodological quality of the included studies (see 'Characteristics of included studies' and risk of bias tables; Figure 2; Figure 3; Summary of findings for the main comparison). The method of concealment of allocation was unclear in three of the six included studies (we have contacted the primary investigators of these three studies and are waiting for them to clarify the method of concealment). Secondly, the total number of participants included in the review was small considering the large number of cataract surgery procedures carried out daily, worldwide. This is compounded by our inability to pool results due to the differences in the methods of reporting the outcome measures. Data could only be pooled for akinesia, for four of the included studies (see Analysis 1.2). In the Friedman 2001b review the included studies were scored for representativeness (37\%), bias and confounding (48\%), description of therapy (35\%), statistical quality and interpretation (39\%), study outcome and follow up (58\%).

\section{AUTHORS' CONCLUSIONS}

\section{Implications for practice}

There is no evidence that peribulbar anaesthesia gives better akinesia and anaesthesia than retrobulbar anaesthesia for cataract surgery. We did not, however, assess pain during injection. There is some evidence that peribulbar anaesthesia causes more conjunctival chemosis than with retrobulbar anaesthesia. The rates of severe local and systemic complications are very rare. There is thus no evidence of a difference in the efficacy and safety profiles for PB and RB for anaesthetists, surgeons or patients.

\section{Implications for research}

There is a need to pay good attention to methodology in research on local anaesthesia for cataract surgery. Outcome measures need to be assessed quantitatively rather than with qualitative measures, for example using visual analogue scores for pain and millimetre movement of each rectus muscle for akinesia.

\section{ACKN OWLEDGEMENTS}

We would like to thank Professor Andrew Smith, Dr Maurizio Solca, Dr Richard Wormald and Professor NL Pace for their help and editorial advice during the preparation of this review. We would also like to thank the Cochrane Eye and Vision Group for their editorial input and the Cochrane Anaesthesia Review Group for providing materials. 


\section{REFERE N CE S}

\section{References to studies included in this review}

Ali-Melkkila 1992 \{published data only\}

Ali Melkkila TM, Virkkila M, Jyrkkio H. Regional anesthesia for cataract surgery: comparison of retrobulbar and peribulbar techniques. Indian Journal of Ophthalmology 1992;39:48-9. [MEDLINE: 1515389]

\section{Ali-Melkkila 1993 \{published data only\}}

Ali-Melkkila T, Markku V, Keino K, Palve H. Regional anaesthesia for cataract surgery: comparison of three techniques [see comments]. British Journal of Ophthalmology 1993;77(12):771-3. [MEDLINE: 8110669]

\section{Athanikar 1991 \{published data only\}}

Athanikar NS, Agrawal VB. One point low volume peribulbar anaesthesia versus retrobulbar anaesthesia a prospective clinical trial. Indian Journal of Ophthalmology 1991;39(2):48-9. [MEDLINE: 1916978]

\section{Feibel 1993 \{published data only\}}

Feibel RM, Custer PL, Gordon MO. Postcataract ptosis. A randomized, double-masked comparison of peribulbar and retrobulbar anesthesia. Ophthalmology 1993;100:660-5. [MEDLINE: 8493007]

\section{Weiss 1989 \{published data only\}}

Weiss JL, Deichman CB. A comparison of retrobulbar and periocular anesthesia for cataract surgery. Archives of Ophthalmology 1989;107:96-8. [MEDLINE: 2910293]

Wong 1993 \{published data only\}

* Wong HW, Koehrer E, Sutton HF. A modified retrobulbar block for eye surgery. Canadian Journal of Anaesthesia (Journal Canadien d'Anesthésie) 1993;40(6):547-53.

\section{References to studies excluded from this review}

\section{Asensio 1994 \{published data only\}}

Asensio SVM, Sanchez BJ, Martin S, Merchan L. Comparison of retrobulbar and peribulbar anaesthesia for cataract surgery. Archivos de la Sociedad Española de Oftalmología 1994;66:171-4. [MEDLINE: 00168753]

\section{Barker 1989 \{published data only\}}

Barker J P, Robinson PN, Vafidis GC, Hart GR, Hall GM. Local anaesthesia for cataract surgery. Lancet 1989;1:393. [MEDLINE: 2563555]

\section{Edge 1995 \{published data only\}}

Edge KR, McClarty CP, Krige SJ, Rantalainan RR. Comparison of an extraconal block with a retrobulbar-facial block combination for ocular surgery. South African Journal of Surgery 1995;33(3):117-20. [MEDLINE: 8607053]

\section{Hessemer 1994 \{published data only\}}

Hessemer V. Peribulbar anesthesia versus retrobulbar anesthesia with facial block. Techniques local anesthetics and additives, akinesia and sensory blockade, complications.
Klinische Monatsblätter für Augenheilkunde 1994;204:75-89. [MEDLINE: 8170098]

\section{Jacobi 2000 \{published data only\}}

Jacobi PC, Dietlein TS, Jacobi FK. A comparative study of topical versus retrobulbar anesthesia in complicated cataract surgery. Archives of Ophthalmology 2000;118(8):1037-43. [MEDLINE: 10982042]

\section{Lavinsky 2000 \{published data only\}}

Lavinsky J, Gus PI, Ehlers JA, Roehe D, Nora DB. Visualevoked potentials: assessment of retrobulbar and peribulbar anesthesia. Journal of Cataract and Refractive Surgery 2000;26:1529-32. [MEDLINE: 11033402]

Murdoch 1990 \{published data only\} Murdoch I. Peribulbar versus retrobulbar anaesthesia. Eye 1990;4:445-9. [MEDLINE: 2209907]

\section{Ramsay 2001 \{published data only\}}

Ramsay AS, Ray Chaudhuri N, Dayan M, Walshaw D. Quantification of relative afferent pupillary defects induced by posterior sub-Tenon's, peribulbar, and retrobulbar anaesthetics. British Journal of Ophthalmology 2001;85:1445-6. [MEDLINE: 11734518]

Ropo 1992 \{published data only\}

Ropo A, Ruusuvaara P Setala K. Visual evoked potentials after retrobulbar or periocular anaesthesia. British Journal of Ophthalmology 1992;76:541-4. [MEDLINE: 1420059]

Sanford 1998 \{published data only\}

Sanford D K, Minoso y de Cal OE, Belyea DA. Response of intraocular pressure to retrobulbar and peribulbar anesthesia. Ophthalmic Surgery and Lasers 1998;29:815-7. [MEDLINE: 9793946]

\section{Saunders 1993 \{published data only\}}

Saunders DC, Sturgess DA, Pemberton CJ, Morgan LH, Bourne A. Peribulbar and retrobulbar anesthesia with prilocaine: a comparison of two methods of local ocular anesthesia. Ophthalmic Surgery 1993;24(12):842-5. [MEDLINE: 8115101]

Whitsett 1990 \{published data only\}

Whitsett J C, Balyeat HD, McClure B. Comparison of oneinjection-site peribulbar anesthesia and retrobulbar anesthesia. Journal of Cataract \& Refractive Surgery 1990;16:527-8. [MEDLINE: 2256971]

\section{References to studies awaiting assessment}

Agrawal 1993 \{published data only\}

Agrawal K, Saxena RC, Nath R. Saxena S. Local anesthesia by peribulbar block for cataract extraction in an eye relief camp. Online Journal of Current Clinical Trials 1993;19:Doc No 40. [MEDLINE: 8306001] 
Li 1996 \{published data only\}

Li H, Li XE. Comparison of retrobulbar and periocular anesthesia for cataract surgery. Journal of Henyang Medical College 1996;24:49-51.

\section{Meyer 1992 \{published data only\}}

Meyer D, Hamilton RC, Loken RG, Bimbel HV. Effect of combined peribulbar and retrobulbar injection of large volume of anesthetic agents on the intraocular pressure. Canadian Journal of Ophthalmology 1992;27:230-2. [MEDLINE: 1393807]

\section{Sanders 1997 \{published data only\}}

Sanders R, Ahmed S, Craig EW, Young JD. Comparison of catecholmine and pressor effects in peribulbar and retrobulbar anaesthesia in cataract surgery. Eye 1997;11:644-8. [MEDLINE: 9474311]

\section{Additional references \\ Davis 1986}

Davis DB 2nd, Mandel MR. Posterior peribulbar anaesthesia: an alternative to retrobulbar anaesthesia. Journal of Cataract and Refractive Surgery 1986;12:182.

\section{Davis 1989}

Davis DB 2nd, Mandel MR. Posterior peribulbar anaesthesia: an alternative to retrobulbar anaesthesia. Indian Journal of Ophthalmology 1989;37:59-61.

\section{Davis 1994}

Davis DB 2nd, Mandel MR. Efficacy and complication rate of 16,224 consecutive peribulbar blocks. A prospective multicentre study. Journal of Cataract \& Refractive Surgery 1994;20(6):263.

\section{Foster 1999}

Foster A. Cataract -- a global perspective: output, outcome and outlay. Eye 1999;13:449-53.

\section{Friedman 2001a}

Friedman DS, Bass EB, Lubomski LH, Fleisher LA, Kempen JH, Magaziner J, et al. Synthesis of the literature on the effectiveness of regional anesthesia for cataract surgery. Ophthalmology 2001;108(3):530-41. [MEDLINE: 11237906]

\section{Friedman 2001b}

Friedman SD, Bass EB, Lubomski LH, Flesher LA, Kempen JH, et al. The methodological quality of clinical trials on

\section{CHARACTERISTICS OF STUDIES}

Characteristics of included studies [ordered by study ID] regional anesthesia for cataract surgery. Opthalmology 2001;108(3):530-41.

\section{Fry 1990}

Fry RA, Henderson J. Local anaesthesia for eye surgery: the peribulbar technique. Anaesthesia 1990;45:14-7.

\section{Hamilton 1988}

Hamilton RC, Gimble HV, Strunin L. Regional anaesthesia for 12,000 cataract extractions and lens implant procedures. Canadian Journal of Anaesthesia 1988;35:615-25.

\section{Hansen 1998}

Hansen TE. Current trend in cataract surgery in Denmark; 1998 survey. Acta Ophthalmologica Scandinavica 1999;77:685-9.

\section{Higgins 2009}

Higgins JPT, Green S, editors. Cochrane Handbook for Systematic Reviews of Interventions Version 5.0.2 [updated September 2009]. The Cochrane Collaboration, 2008. Available from www.cochrane-handbook.org.

\section{Leaming 1999}

Leaming DV. Practice styles and preferences of ASCRS members - 1998 survey. Journal of Cataract and Refractive Surgery 1999;25:851-9.

\section{RevMan 5.0 [Computer program]}

The Nordic Cochrane Centre, The Cochrane Collaboration. Review Manager (RevMan). Version 5.0. Copenhagen: The Nordic Cochrane Centre, The Cochrane Collaboration, 2007.

\section{Springs 2001}

Springs CL, Broocker G. Injectional Orbital Anesthesia for Cataract Surgery. Survey of Ophthalmology 2001;46:181-4.

\section{References to other published versions of this review Alhassan 2008 \\ Alhassan MB, Kyari F, Ejere HOD. Peribulbar versus retrobulbar anaesthesia for cataract surgery. Cochrane Database of Systematic Reviews 2008, Issue 3. [DOI: 10.1002/14651858.CD004083.pub2]}

* Indicates the major publication for the study

Ali-Melkkila 1992

Methods RCT. Allocation concealment not clear; masking of participants and primary investigators, and masking of outcome measure assessment were not reported.

Participants In Finland, 300 patients undergoing ambulatory elective cataract extraction and intraocular lens implantation. Mean age of participants 68 years. 
Ali-Melkkila 1992 (Continued)

Interventions
Periocular anaesthesia using $5 \mathrm{cc}$ of anaesthetic agent injected $1 \mathrm{~cm}$ medial to the lateral canthus with a $25 \mathrm{~mm}$ needle (142) versus retrobulbar anaesthesia using $4 \mathrm{ml}$ of anaesthetic agent injected into the muscle cone through the inferolateral lower lid with $30 \mathrm{~mm}$ needle. Premedication with alfentanil 15 minutes before anaesthesia. All blocks were given with a 50:50 mixture of $0.5 \%$ bupivacaine and $2 \%$ lidocaine with 1:100000 adrenaline and 150 IU hyaluronidase. Mechanical orbital compression applied for 15 minutes.
Outcomes
Globe akinesia, supplemental block, complications.

Notes

\section{Risk of bias}

Bias Authors' judgement Support for judgement

Random sequence genera- High risk Sequence generation was not defined properly

tion (selection bias)

\begin{tabular}{ll}
\hline $\begin{array}{l}\text { Allocation concealment } \\
\text { (selection bias) }\end{array}$ & $\begin{array}{l}\text { Unclear risk } \\
\text { anaesthesia }\end{array}$
\end{tabular}

Blinding (performance Unclear risk Blinding method was stated

bias and detection bias)

All outcomes

\begin{tabular}{lll}
\hline $\begin{array}{l}\text { Selective reporting (re- } \\
\text { porting bias) }\end{array}$ & Low risk & All data reported \\
\hline Other bias & Low risk & Free of publication bias \\
\hline
\end{tabular}

Ali-Melkkila 1993

\begin{tabular}{ll} 
Methods & $\begin{array}{l}\text { RCT. Allocation concealment unclear; masking of participants and primary investigators not adequate, } \\
\text { masking of outcome assessment adequate. }\end{array}$ \\
\hline
\end{tabular}

\begin{tabular}{ll}
\hline Participants & In Finland, 450 patients undergoing elective cataract extraction. \\
\hline Interventions & $\begin{array}{l}\text { Three groups of patients: group 'R' received retrobulbar anaesthesia, group 'P1' periocular injection } \\
\text { given inferotemporally and superonasally, group 'P11' periocular injection given inferotemporally and } \\
\text { into the medial compartment of the orbit. All blocks were performed with a solution of } 2 \% \text { lidocaine } \\
\text { with 1:100000 adrenaline and } 0.5 \% \text { bupivacaine with } 75 \text { IU hyaluronidase. }\end{array}$ \\
\hline Outcomes & Extraocular muscle akinesia. \\
\hline Notes &
\end{tabular}

\section{Risk of bias}

\begin{tabular}{lll}
\hline Bias & Authors' judgement & Support for judgement \\
\hline $\begin{array}{l}\text { Random sequence genera- } \\
\text { tion (selection bias) }\end{array}$ & High risk & Patients were divided into three groups in consecutive order \\
\hline $\begin{array}{l}\text { Allocation concealment } \\
\text { (selection bias) }\end{array}$ & Unclear risk & Method of randomization not clearly stated \\
\hline
\end{tabular}


Ali-Melkkila 1993 (Continued)

Blinding (performance Low risk The outcome assessor was not aware of the type of anaesthesia administered
bias and detection bias)

All outcomes

\begin{tabular}{lll}
\hline $\begin{array}{l}\text { Selective reporting (re- } \\
\text { porting bias) }\end{array}$ & Low risk & All data reported on \\
\hline Other bias & Low risk & Free of publication bias \\
\hline
\end{tabular}

Athanikar 1991

\begin{tabular}{ll} 
Methods & $\begin{array}{l}\text { RCT. Allocation by randomization chart, masking of participants and primary investigators was ade- } \\
\text { quate. }\end{array}$ \\
\hline Participants & In India, 142 patients undergoing cataract surgery. \\
\hline Interventions & $\begin{array}{l}\text { Peribulbar anaesthesia }(71)(5 \mathrm{cc} \text { of anaesthetic using a } 3.75 \mathrm{~cm} \text { needle placed at the junction of medi- } \\
\text { al } 2 / 3 \text { and the lateral } 1 / 3 \mathrm{cf} \text { the inferior orbital rim and directed backwards and upwards) versus retrob- } \\
\text { ulbar anaesthesia ( } 71)(5 \mathrm{cc} \text { of anaesthetic agent injected with a } 1.5 \mathrm{~cm} \text { needle directed straight down, } \\
\text { with the needle buried up to the hub at the skin). A mixture of lidocaine } 2 \%+1: 200000+\text { hyaluronidase } \\
\text { was used for both groups. No facial blocks or additional injection for lid akinesia. Pinky ball pressure } \\
\text { was applied for } 10 \text { minutes. All injections were given with a mixture of } 2 \% \text { lidocaine, } 1: 200000 \text { adrena- } \\
\text { line and } 150 \text { IU hyaluronidase. }\end{array}$ \\
\hline
\end{tabular}

Outcomes Lid akinesia and globe akinesia graded on a scale of 0 to +++ , number of participants that developed
complications.

\section{Notes}

\section{Risk of bias}

\begin{tabular}{|c|c|c|}
\hline Bias & Authors' judgement & Support for judgement \\
\hline $\begin{array}{l}\text { Random sequence genera- } \\
\text { tion (selection bias) }\end{array}$ & Low risk & By randomization chart \\
\hline $\begin{array}{l}\text { Allocation concealment } \\
\text { (selection bias) }\end{array}$ & Unclear risk & The method of allocation concealment not clear \\
\hline $\begin{array}{l}\text { Blinding (performance } \\
\text { bias and detection bias) } \\
\text { All outcomes }\end{array}$ & Low risk & Administration and evaluation done by separate person \\
\hline $\begin{array}{l}\text { Selective reporting (re- } \\
\text { porting bias) }\end{array}$ & Low risk & All data reported \\
\hline Other bias & Low risk & Free of publication bias \\
\hline
\end{tabular}

\section{Feibel 1993}

$\begin{array}{ll}\text { Methods } & \text { RCT. Allocation concealment adequate; masking of participants and primary investigators adequate, } \\ \text { masking of outcome assessment adequate. }\end{array}$


Feibel 1993 (Continued)

Participants In USA, 317 patients receiving cataract surgery.

\begin{tabular}{ll}
\hline Interventions & Two injection periocular anaesthesia versus retrobulbar anaesthesia. Anaesthetic injection consisted \\
of $0.375 \%$ bupivacaine, $1 \%$ mepivacaine and hyaluronidase. No orbital compression was used.
\end{tabular}

Outcomes Postcataract surgery ptosis.

Notes

\section{Risk of bias}

\begin{tabular}{lll}
\hline Bias & Authors' judgement & Support for judgement \\
\hline $\begin{array}{l}\text { Random sequence genera- } \\
\text { tion (selection bias) }\end{array}$ & Low risk & Randomization to retrobulbar or peribulbar injection was decided by coin toss \\
\hline $\begin{array}{l}\text { Allocation concealment } \\
\text { (selection bias) }\end{array}$ & Unclear risk & The method of allocation was unclear \\
\hline $\begin{array}{l}\text { Blinding (performance } \\
\text { bias and detection bias) } \\
\text { All outcomes }\end{array}$ & Low risk & Adiministrator of injection different from the assessor of ptosis \\
\hline $\begin{array}{l}\text { Selective reporting (re- } \\
\text { porting bias) }\end{array}$ & Low risk & All data reported on \\
\hline \begin{tabular}{l} 
Other bias \\
\hline
\end{tabular} & Low risk & Free of publication bias \\
\hline
\end{tabular}

Weiss 1989

\begin{tabular}{ll}
\hline Methods & $\begin{array}{l}\text { RCT. Allocation concealment unclear; masking of participants and primary investigators adequate, } \\
\text { masking of outcome assessment adequate. }\end{array}$ \\
\hline Participants & $\begin{array}{l}79 \text { consecutive patients that received cataract extraction with intraocular lens implants at the Mary } \\
\text { Imogene Bassett Hospital, Cooperstown, NY. }\end{array}$ \\
\hline Interventions & $\begin{array}{l}\text { Periocular anaesthesia versus retrobulbar anaesthesia, each patient received } 0.5 \text { to } 1.0 \mathrm{mg} \text { of intra- } \\
\text { venous idazolam administered by ophthalmic resident, identical mixture of anaesthetic: } 50: 50 \text { mixture } \\
\text { of } 2 \% \text { lidocaine and } 0.75 \% \text { bupivacaine with } 1: 200000 \text { epinephrine, honan pressure balloon set at } 30 \\
\text { mm Hg was placed immediately following the administration of anaesthetic and left for } 10 \text { minutes. }\end{array}$
\end{tabular}

Outcomes Globe anaesthesia, glove akinesia, lid akinesia, supplemental blocks, complications.

Notes

\begin{tabular}{lll}
\hline Risk of bias & Authors' judgement & Support for judgement \\
\hline Bias & Unclear risk & $\begin{array}{l}\text { Patients were randomized as to whether they will receive retrobulbar or peri- } \\
\text { ocular anaesthesia. The method not clearly stated }\end{array}$ \\
\hline $\begin{array}{l}\text { Random sequence genera- } \\
\text { tion (selection bias) }\end{array}$ & $\begin{array}{l}\text { No information given on the method of concealment allocation used in the tri- } \\
\text { al }\end{array}$ \\
\hline $\begin{array}{l}\text { Allocation concealment } \\
\text { (selection bias) }\end{array}$ & Unclear risk & \\
\hline
\end{tabular}


Weiss 1989 (Continued)

Blinding (performance Low risk Anaesthetist administered the injection while the Surgeon did the assessment bias and detection bias)

All outcomes

\begin{tabular}{lll}
\hline $\begin{array}{l}\text { Selective reporting (re- } \\
\text { porting bias) }\end{array}$ & Low risk & All data reported on \\
\hline Other bias & Low risk & Free of publication bias \\
\hline
\end{tabular}

Wong 1993

\begin{tabular}{|c|c|c|}
\hline Methods & \multicolumn{2}{|c|}{$\begin{array}{l}\text { RCT. Allocation concealment clear; masking of participants and primary investigators adequate, mask- } \\
\text { ing of outcome assessment adequate. }\end{array}$} \\
\hline Participants & \multicolumn{2}{|c|}{$\begin{array}{l}150 \text { patients of one surgeon who were having cataract surgery at Vancouver General Hospital, Canada. } \\
\text { Age range } 21-95 \text { years. }\end{array}$} \\
\hline Interventions & \multicolumn{2}{|c|}{$\begin{array}{l}\text { Retrobulbar block ( } 50 \text { patients): received } 4 \mathrm{ml} \text { of anaesthetic; peribulbar block ( } 50 \text { patients): received } 7 \\
\mathrm{ml} \text { of anaesthetic; and modified retrobulbar block ( } 50 \text { patients): received } 4.5 \mathrm{ml} \text { of anaesthetic. }\end{array}$} \\
\hline Outcomes & \multicolumn{2}{|c|}{ Akinesia, analgesia, orbital pressure, block supplementation, complications, patient satisfaction. } \\
\hline \multicolumn{3}{|l|}{ Notes } \\
\hline \multicolumn{3}{|l|}{ Risk of bias } \\
\hline Bias & Authors' judgement & Support for judgement \\
\hline $\begin{array}{l}\text { Random sequence genera- } \\
\text { tion (selection bias) }\end{array}$ & Low risk & Patients were randomly assigned by draw to one of the three blocks \\
\hline $\begin{array}{l}\text { Allocation concealment } \\
\text { (selection bias) }\end{array}$ & Unclear risk & Allocation was by nurse drawing from an envelope \\
\hline $\begin{array}{l}\text { Blinding (performance } \\
\text { bias and detection bias) } \\
\text { All outcomes }\end{array}$ & Low risk & Outcome assessor was not aware of the type of intervention \\
\hline $\begin{array}{l}\text { Selective reporting (re- } \\
\text { porting bias) }\end{array}$ & Low risk & All data reported on \\
\hline Other bias & Low risk & Free of publication bias \\
\hline
\end{tabular}

\section{Characteristics of excluded studies [ordered by study ID]}

\begin{tabular}{ll}
\hline Study & Reason for exclusion \\
\hline Asensio 1994 & $\begin{array}{l}\text { Concealment of allocation was unclear; masking of participants and primary investigators and } \\
\text { masking of outcome assessment were unclear. }\end{array}$ \\
\hline Barker 1989 & Not a study: a letter to the editor. \\
\hline
\end{tabular}




\begin{tabular}{|c|c|}
\hline Study & Reason for exclusion \\
\hline Edge 1995 & $\begin{array}{l}\text { Concealment of allocation was unclear, masking of participants and primary investigators and } \\
\text { masking of outcome assessment were unclear. }\end{array}$ \\
\hline Hessemer 1994 & Outcome measures not clearly stated. Did not report any of the outcome measures for this review. \\
\hline Jacobi 2000 & The trial compared topical anaesthesia with retrobulbar anaesthesia in complicated cataract. \\
\hline Lavinsky 2000 & $\begin{array}{l}\text { Concealment of allocation was unclear, masking of participants and primary investigators and } \\
\text { masking of outcome assessment were unclear. }\end{array}$ \\
\hline Murdoch 1990 & $\begin{array}{l}\text { Concealment of allocation inadequate, masking of participants and primary investigators inade- } \\
\text { quate and masking of outcome assessment unclear. }\end{array}$ \\
\hline Ramsay 2001 & $\begin{array}{l}\text { The study compared sub-tenons, peribulbar and retrobulbar anaesthesia. The outcome measures } \\
\text { were not included in our review. }\end{array}$ \\
\hline Ropo 1992 & The study objective is the effect of an anaesthetic agent on the optic nerve head. \\
\hline Sanford 1998 & The study included participants who had trabeculectomy. \\
\hline Saunders 1993 & The outcome measure of the study was not relevant to our review. \\
\hline Whitsett 1990 & $\begin{array}{l}\text { Concealment allocation unclear; masking of participants and primary investigators unclear and } \\
\text { masking of outcome assessment inadequate. }\end{array}$ \\
\hline
\end{tabular}

Characteristics of studies awaiting assessment [ordered by study ID]

\begin{tabular}{|c|c|}
\hline Methods & Double-blinded RCT. \\
\hline Participants & 122 patients eligible for intracapsular cataract extraction under local anaesthesia. \\
\hline Interventions & $\begin{array}{l}\text { Peribulbar or retrobulbar anaesthesia; infiltrated with } 5 \mathrm{ml} \text { of the same anaesthetic at the same } \\
\text { site but with different needle size. }\end{array}$ \\
\hline Outcomes & $\begin{array}{l}\text { Globe anaesthesia (primary outcome), globe akinesia, lid akinesia, pupillary dilatation, and hy- } \\
\text { potony scored separately on a 4-point scale during surgery by a masked surgeon. }\end{array}$ \\
\hline Notes & Unable to acquire full content paper. \\
\hline \multicolumn{2}{|l|}{ Li 1996} \\
\hline Methods & Comparison. \\
\hline Participants & Cataract surgery patients. \\
\hline Interventions & Retrobulbar and periocular anaesthesia. \\
\hline Outcomes & Not clear from the available data. \\
\hline Notes & Incomplete abstract. Need to get full content paper. \\
\hline
\end{tabular}


Meyer 1992

Methods

Prospective RCT, 79 patients undergoing elective routine cataract surgery using Kelman phacoemulsification technique. Group 1 (39 patients) received PB while group 2 (40 patients) received RB. Both groups received a total of $10.5 \mathrm{ml}$ of local anaesthetic.

\begin{tabular}{ll}
\hline Participants & 79 patients undergoing cataract surgery. \\
\hline Interventions & Peribulbar and retrobulbar anaesthesia. \\
\hline Outcomes & Mean intraocular pressure elevation. \\
\hline Notes &
\end{tabular}

\section{Sanders 1997}

Methods RCT. Comparison of plasma catecholamine and pressor effects between the two methods of anaes-
thesia in 40 patients.

\begin{tabular}{ll}
\hline Participants & Cataract surgery patients. \\
\hline Interventions & Peribulbar and retrobulbar anaesthesia. \\
\hline Outcomes & Plasma adrenaline and noradrenaline, heart rate. \\
\hline
\end{tabular}

Notes

\section{DATA AND ANALYSES}

Comparison 1. Peribulbar versus retrobulbar

\begin{tabular}{llllll}
\hline Outcome or subgroup title & $\begin{array}{l}\text { No. of } \\
\text { studies }\end{array}$ & $\begin{array}{l}\text { No. of } \\
\text { partici- } \\
\text { pants }\end{array}$ & Statistical method & Effect size \\
\hline 1 Pain score & 2 & 221 & Mean Difference (IV, Fixed, 95\% Cl) & $-0.03[-0.17,0.11]$ \\
\hline 2 Globe akinesia & 4 & 1042 & Risk Ratio (M-H, Random, 95\% Cl) & $0.98[0.88,1.09]$ \\
\hline 3 Need for additional injection & 4 & 1029 & Risk Ratio (M-H, Random, 95\% Cl) & $1.54[0.91,2.60]$ \\
\hline 4 Local complications & 5 & & Risk Ratio (M-H, Fixed, 95\% Cl) & Subtotals only \\
\hline 4.1 Retrobular haemorrhage & 1 & 142 & Risk Ratio (M-H, Fixed, 95\% Cl) & 0.33 [0.01, 8.05] \\
\hline 4.2 Conjunctival chemosis & 4 & 1042 & Risk Ratio (M-H, Fixed, 95\% Cl) & $2.11[1.46,3.05]$ \\
\hline 4.3 Lid haematoma & 1 & 450 & Risk Ratio (M-H, Fixed, 95\% Cl) & $0.36[0.15,0.88]$ \\
\hline 4.4 Ptosis & 1 & 317 & Risk Ratio (M-H, Fixed, 95\% Cl) & $1.06[0.43,2.60]$ \\
\hline
\end{tabular}




\begin{tabular}{lllll}
\hline Outcome or subgroup title & $\begin{array}{l}\text { No. of } \\
\text { studies }\end{array}$ & $\begin{array}{l}\text { No. of } \\
\text { partici- } \\
\text { pants }\end{array}$ & Statistical method & Effect size \\
\hline 5 Acceptability of blocks & 2 & 600 & Risk Ratio (M-H, Fixed, 95\% Cl) & $1.01[0.98,1.03]$ \\
\hline
\end{tabular}

Analysis 1.1. Comparison 1 Peribulbar versus retrobulbar, Outcome 1 Pain score.

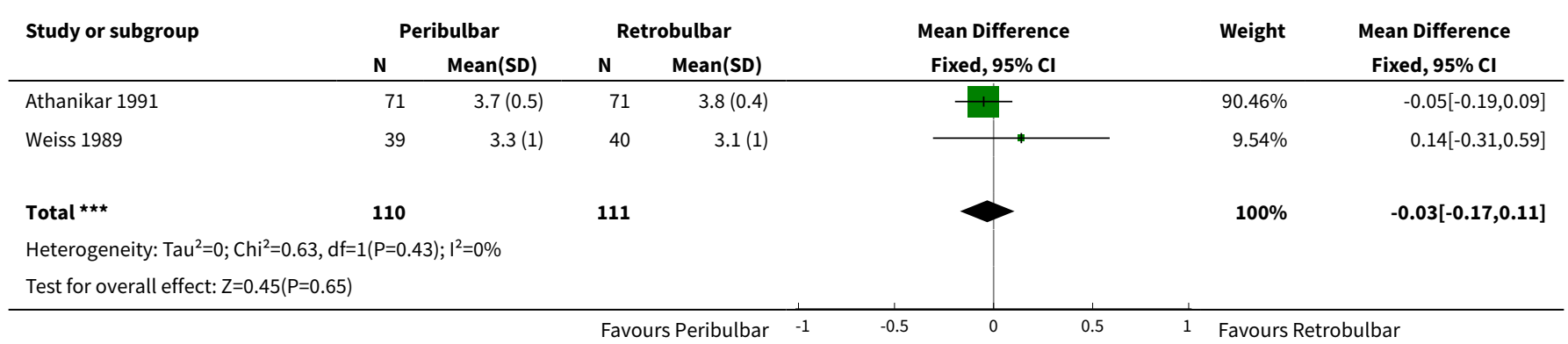

Analysis 1.2. Comparison 1 Peribulbar versus retrobulbar, Outcome 2 Globe akinesia.

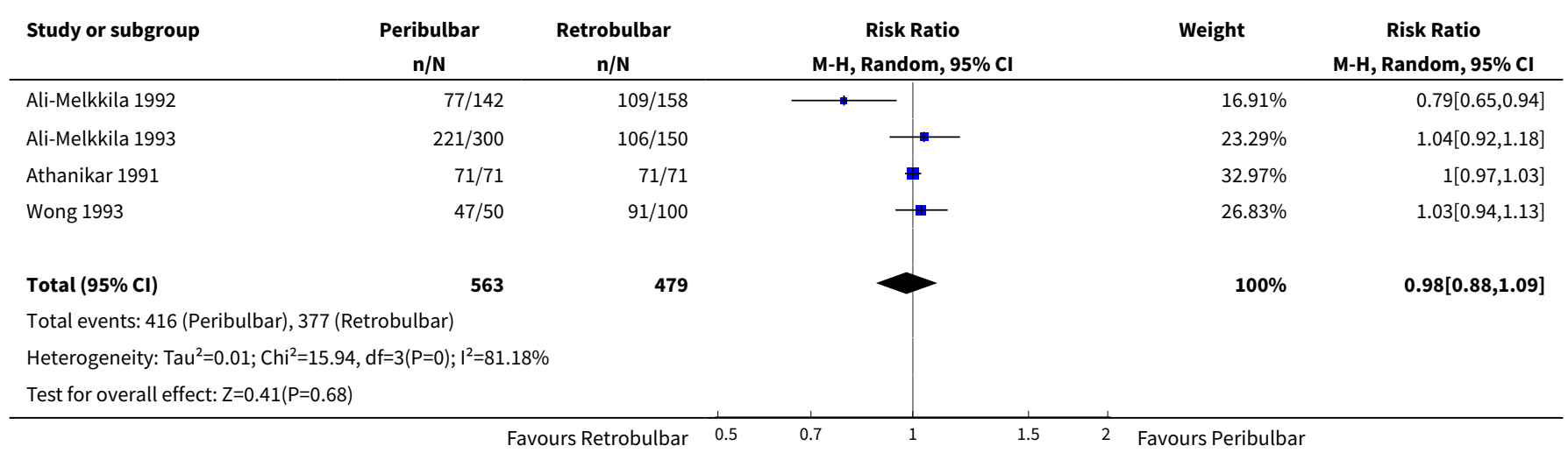

Analysis 1.3. Comparison 1 Peribulbar versus retrobulbar, Outcome 3 Need for additional injection.

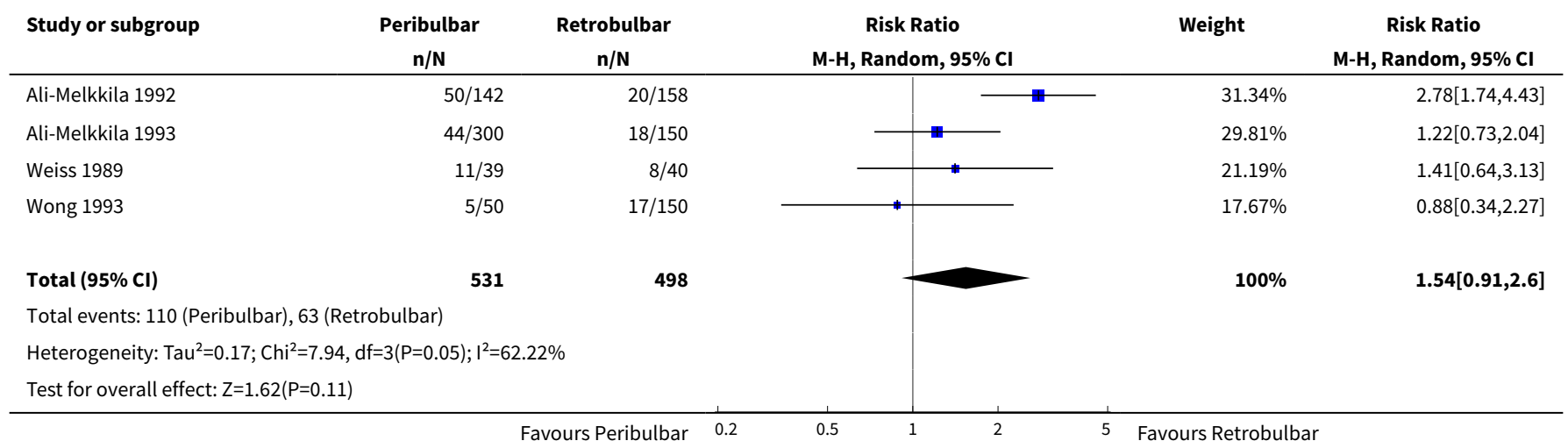


Analysis 1.4. Comparison 1 Peribulbar versus retrobulbar, Outcome 4 Local complications.

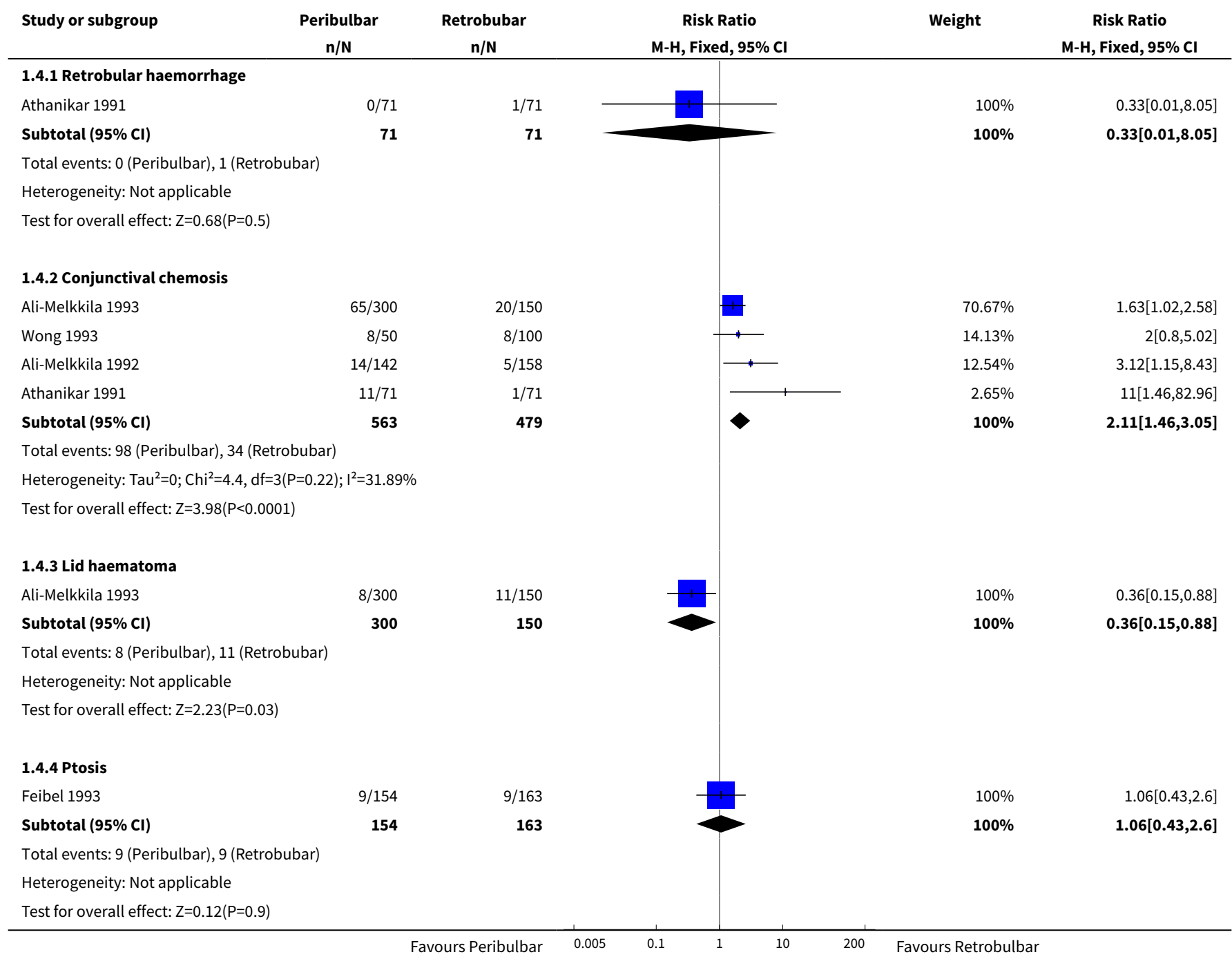

\section{Analysis 1.5. Comparison 1 Peribulbar versus retrobulbar, Outcome 5 Acceptability of blocks.}

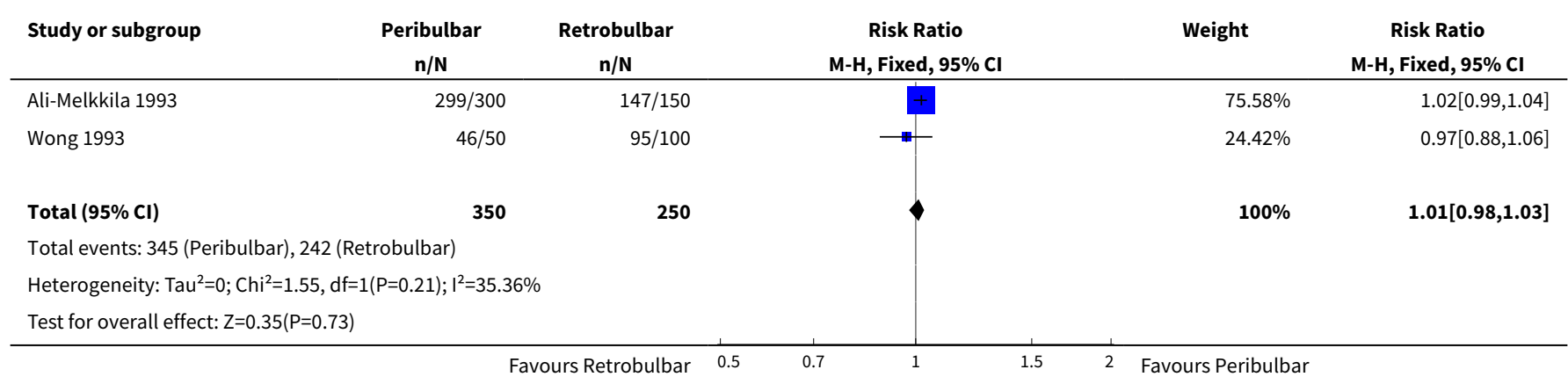




\section{APPENDICES}

\section{Appendix 1. The Central March 2015}

\#1 MeSH descriptor Anesthesia, Conduction, this term only

\#2 ((regional or local or peribulbar or retrobulbar or peri-bulbar or retro-bulbar or intraconal or periocular or intra-conal or peri-ocular) and anesthe $\left.{ }^{\star}\right)$

\#3 ((regional or local or peribulbar or retrobulbar or peri-bulbar or retro-bulbar or intraconal or periocular or intra-conal or peri-ocular) and block*)

\#4 (\#1 OR \#2 OR \#3)

\#5 MeSH descriptor Lens Implantation, Intraocular explode all trees

\#6 MeSH descriptor Lenses, Intraocular explode all trees

\#7 MeSH descriptor Cataract Extraction explode all trees

\#8 (cataract $^{\star}$ near extract ${ }^{\star}$ )

\#9 (cataract* near surgery)

\#10 (senile near cataract ${ }^{\star}$ )

$\# 11$ (age-related near cataract ${ }^{\star}$ )

$\# 12$ halogenous

\#13 (\#5 OR \#6 OR \#7 OR \#8 OR \#9 OR \#10 OR \#11 OR \#12)

\#14 (\#4 AND \#13)

\section{Appendix 2. Ovid MEDLINE (1960 to March 2015)}

1. exp Cataract-extraction/ or Lens-implantation-intraocular/ or LENSES/ or LENSES-INTRAOCULAR/ or (cataract* and (surgery or extract* or senile or age?related)).mp. or cataract*.ti,ab. or halogenous.mp.

2. exp Anesthesia-Conduction/ or ((regional or local or peri?bulbar or retro?bulbar or intra?conal or peri?ocular) and (an?esthe* or block $\left.{ }^{\star}\right)$ ).mp.

3. 1 and 2

4. ((randomized controlled trial or controlled clinical trial).pt. or randomized.ab. or placebo.ab. or drug therapy.fs. or randomly.ab. or trial.ab. or groups.ab.) not (animals not (humans and animals)).sh.

5. 3 and 4

\section{Appendix 3. Ovid EMBASE (1980 to March 2015)}

1. exp regional-anesthesia/ or ((regional or local or peri?bulbar or retro?bulbar or intra?conal or peri?ocular) and (an?esthe* or block ? $\left.^{\star}\right)$.mp. 2. exp cataract-extraction/ or exp lens-implant/ or lens-implantation/ or lens-/ or lens-implant/ or (cataract ${ }^{\star}$ and (surgery or extract* or senile or age?related)).mp. or cataract ${ }^{\star}$.ti,ab. or halogenous.mp.

3. 1 and 2

4. (randomized-controlled-trial/ or randomization/ or controlled-study/or multicenter-study/or phase-3-clinical-trial/ or phase-4-clinicaltrial/ or double-blind-procedure/ or single-blind-procedure/ or (random* or cross?over ${ }^{\star}$ or factorial* or placebo* or volunteer* or ((singl ${ }^{\star}$ or doubl* or trebl* or tripl*) adj3 (blind* or mask $\left.{ }^{\star}\right)$ )).ti,ab.) not (animals not (humans and animals)).sh.

5. 3 and 4

\section{WHAT'S NEW}

\begin{tabular}{lll}
\hline Date & Event & Description \\
\hline 26 June 2015 & $\begin{array}{l}\text { New citation required but conclusions } \\
\text { have not changed }\end{array}$ & Search updated - no new studies found. \\
\hline 26 June 2015 & New search has been performed & $\begin{array}{l}\text { In the previous updated version of our review (Alhassan 2008), } \\
\text { we searched the databases until September 2010. In this cur- } \\
\text { rent updated version we reran the database searches until March } \\
\text { 2015. We did not find any new studies which fitted our inclusion } \\
\text { criteria. }\end{array}$ \\
\hline
\end{tabular}

\section{H I S T O R Y}

Protocol first published: Issue 1, 2003

Peribulbar versus retrobulbar anaesthesia for cataract surgery (Review) 


\begin{tabular}{lll}
\hline Date & Event & Description \\
\hline 15 March 2011 & New search has been performed & $\begin{array}{l}\text { In the previous version of our review, we searched the databases } \\
\text { until December 2007. In this updated version we reran the data- } \\
\text { base searches until September 2010. We did not find any new } \\
\text { studies which fitted our inclusion criteria. We updated our meth- } \\
\text { ods section and included risk of bias and summary of findings ta- } \\
\text { bles. }\end{array}$
\end{tabular}

bles.

\section{CONTRIBUTIONS OF AUTHORS}

Conceiving the review: Mahmoud Alhassan (MA)

Co-ordinating the review: MA

Undertaking manual searches:MA, Fatima Kyar (FK), Henry Ejere (HE)

Screening search results: $M A, F K, H E$

Organizing retrieval of papers: $\mathrm{MA}, \mathrm{FK}, \mathrm{HE}$

Screening retrieved papers against inclusion criteria: MA, FK, HE

Appraising quality of papers: MA, FK, HE

Abstracting data from papers: MA, FK

Writing to authors of papers for additional information: MA

Providing additional data about papers:

Obtaining and screening data on unpublished studies:

Data management for the review: MA, FK, HE

Entering data into Review Manager (RevMan 5.0): MA, FK, HE

RevMan statistical data: MA, FK

Other statistical analysis not using RevMan:

Double entry of data: (data entered by person one: MA; data entered by person two: FK)

Interpretation of data: MA, FK, HE

Statistical inferences: MA, FK, HE

Writing the review: MA, FK, HE

Securing funding for the review: MA, FK, HE

Performing previous work that was the foundation of the present study:

Guarantor for the review (one author): MA

Person responsible for reading and checking review before submission: MA

\section{DECLARATIONS OF INTEREST}

None known

Peribulbar versus retrobulbar anaesthesia for cataract surgery (Review) 


\section{SOURCES OF SUPPORT}

\section{Internal sources}

- National Eye Centre, Kaduna, Nigeria.

\section{External sources}

- Cochrane Anaesthesia Review Group, Denmark.

- UK Cochrane Centre, UK.

- Cochrane Eye and Vision Group, UK.

\section{INDEX TERMS}

\section{Medical Subject Headings (MeSH)}

Anesthesia, Local [adverse effects] [ ${ }^{*}$ methods]; Cataract Extraction [ ${ }^{*}$ methods]; Nerve Block [adverse effects] [ ${ }^{*}$ methods]; Pain Measurement; Randomized Controlled Trials as Topic

\section{MeSH check words}

Humans 